\title{
Clinical Psychology Issues in Migraine Headaches
}

\author{
Patrick J. McGrath
}

\begin{abstract}
The important developments in our understanding and harnessing the biology of migraine have not diminished the need to consider the psychology of migraine. Psychological treatments especially relaxation training and biofeedback have been well validated as effective in treating frequent migraine. When the frequency and severity of migraine warrants more than analgesics, these treatments are the first line treatment for adults who cannot or do not wish to take abortive or prophylactic medications and for adolescents. The use of psychological interventions to enhance compliance to treatment or treatment effects is an underutilized resource. Psychological measurement is also critical in development and understanding of quality of life scales and the examination of decision-making by patients in taking medication. Modern clinical psychology has much to offer in the study of migraine and the amelioration of suffering from this common problem.
\end{abstract}

RÉSUMÉ: Problèmes de psychologie clinique dans la migraine. Les développements importants dans notre compréhension et notre maîtrise de la biologie de la migraine n’ont pas altéré la nécessité de considérer la psychologie de la migraine. Les traitements psychologiques, surtout l'entraînement à la relaxation et à la rétroaction biologique ont été validés adéquatement comme étant efficaces dans le traitement des accès fréquents de migraine. Quand la fréquence et la sévérité de la migraine justifie la prescription de médicaments autres que des analgésiques, ces traitements sont indiqués en première ligne pour les adultes qui ne peuvent pas ou ne veulent pas prendre un médicament faisant avorter la crise ou la prévenant et pour les adolescents. L'utilisation des interventions psychologiques pour augmenter la compliance au traitement ou les effets du traitement est une ressource sous utilisée. L'évaluation psychologique est également un aspect important pour le développement et la compréhension des échelles de qualité de vie et l'examen de la prise de décision par les patients qui prennent une médication. La psychologie clinique moderne a beaucoup à offrir à l'étude de la migraine et à l'amélioration du fardeau de souffrance dû à ce problème fréquent.

Can. J. Neurol. Sci. 1999; 26: Suppl. 3-S33-S36

In spite of the phenomenal advances made in the pharmacological treatment and biological understanding of migraine headaches, there is an important place for scientific contributions to the understanding and treatment of migraine from a psychological perspective. These contributions are in the form of scientifically validated psychological treatments for migraine, interventions to enhance efficacy of pharmacological interventions and understanding of the impact and triggering of migraine. Psychological methods have not been helpful in defining a migraine personality nor have psychological causes been found to be important in the cause of migraine.

The psychological treatments of migraine headache that have been empirically validated as being effective in well-controlled trials are those deriving from behavioural and cognitive behavioural psychology. These treatments include: finger temperature biofeedback, cephalic artery biofeedback, relaxation training and cognitive therapy. Operant treatment in which reinforcers are manipulated to increase healthy behaviours and pain behaviours are punished or extinguished has been widely used in chronic pain treatments but has not been widely studied in migraine. Recent work in teaching parents to support healthy coping and encourage participation in treatment ${ }^{1}$ is promising. Newer applications of behavioural treatments have been shown to be useful in strengthening the effects of pharmacological treatment by improving compliance or by augmenting the effects of medication. Other innovative strategies based on an understanding of patient decision-making may be developed to enhance medical treatment using the "triptans".

From the Department of Psychology, Pediatrics and Psychiatry, Dalhousie University, Pain Service, IWK Grace Health Centre, Halifax, Nova Scotia, Canada. Reprint requests to: PJMcGrath, Department of Psychology, Pediatrics and Psychiatry, Dalhousie University, Pain Service, IWK Grace Health Centre, P.O. Box 3070, Halifax, Nova Scotia B3J 3G9 


\section{BIOFEEDBACK}

Biofeedback involves the use of sensors to detect changes in physiological responses. This information, which is usually in the form of an auditory or visual signal, is then relayed to the patient in real time. The patient uses this information to change the response. Patients may be instructed in ways of changing the biological signal, especially by using relaxation, and are also encouraged to try "whatever works".

In finger temperature biofeedback, the patient typically attempts to warm the hands, although hand cooling has also been shown to be effective. The patient is encouraged to use imagery, suggestion and relaxation to warm the hands. The patient is signalled of changes in finger temperature by an auditory or visual signal. Practice at home is possible with very inexpensive thermometers.

Cephalic artery biofeedback has also been shown to be effective in migraine. ${ }^{2}$ The signals are obtained by reflectance photoplethysmography. The equipment is expensive and obtaining a clean signal is significantly more technically difficult than other types of biofeedback. Equipment for home practice is not available. As a result, cephalic artery biofeedback is seldom used clinically.

Muscle tension biofeedback is also possible with migraine but is more commonly used in tension-type headaches.

\section{RELAXATION THERAPY}

There are three major types of relaxation training: relaxation with tension, relaxation using imagery and suggestion, and relaxation induced by breathing exercises. A fourth type of relaxation is relaxation induced by hypnosis.

Relaxation with tension was first developed by Jacobsen in the $1930 \mathrm{~s}^{3}$ and applied to a wide variety of disorders. The basic strategy is to tense isolated muscle groups for about five seconds and then relax them. Different muscle groups are tensed and relaxed in turn. The tension phase assists in learning relaxation by providing a sharp contrast between tension and relaxation. Moreover, the tension appears to prompt a relaxation rebound. Relaxation using imagery and suggestion is based on work by Shultz and Luthe. ${ }^{4}$ Suggestions of heaviness and warmth in specific muscle groups and visualizing pleasant images are used to induce muscle relaxation. Relaxation induced by breathing exercises was popularized by Benson ${ }^{5}$ but is based on eastern meditative practices. Slow, deep, breaths are used to induce muscle relaxation. Hypnotic induction of relaxation varies with the hypnotic technique used. All hypnosis techniques have the common elements of focusing of attention and repeated suggestions. Hypnosis has the disadvantage of being commonly understood as giving up control to the hypnotist. As well, some religions ban the use of hypnotism by their adherents.

Typically, all forms of relaxation training involve officebased instruction and then home practice, often using an audiotape. Most commonly, a combination of strategies is taught and patients are encouraged to use the methods that work best. For example, relaxation with tension, relaxation using suggestions and imagery and breathing exercises will be taught. The patient will practice different styles of relaxation and will eventually select the method with which he or she is most comfortable. Generalization to everyday activities is taught by having the patient use a very short relaxation induction several times throughout the day and by learning to relax specific parts of the body while maintaining the tension needed for activities. For example, the shoulders and jaw can be quite relaxed while working on the computer.

\section{COGNITIVE THERAPY}

Cognitive therapy is based on the pioneering work of Beck ${ }^{6}$ in depression. The focus is on teaching patients to become aware of what they are thinking about stressful situations and to challenge non-productive patterns of thinking. Often this is cast in terms of what they are saying to themselves consciously or at a level below awareness. Irrational self-statements and erroneous beliefs contributing to patient distress are also contested. A particular style of self-statement or cognitive style that is often the target of intervention is the use of catastrophizing. ${ }^{7}$ When catastrophizing, the patient thinks that excessively negative outcomes will occur. For example, "It will be terrible if my coworkers do not appreciate my efforts," or "I will be unable to go on if I have one more migraine." Cognitive therapy is usually combined with some form of relaxation.

\section{Clinical use}

Psychological treatments are typically delivered in 10-12, 4560 minute sessions. The patient is given a rationale for treatment that is usually based on stress being a modulator or trigger for migraine, which is a neurovascular genetic disorder. The emphasis is on learning self control, so that the patient can identify stress and control the reactions to stress, and thus reduce headache. Sessions consist of discussion, instruction and inoffice practice. Role playing may also be used. Patients are typically given audiotapes to assist in their practice of relaxation at home. Patients are expected to practice relaxation 5-7 days a week. Other skills that are learned in sessions (e.g. partial relaxation, cognitive skills) are applied in everyday life.

\section{EFFICACY}

Various forms of relaxation are often used and there is little evidence to distinguish their efficacy from each other. However, there may be some advantage to combining relaxation with biofeedback or cognitive therapy. ${ }^{8}$

The efficacy of psychological treatments for migraine has been well-established in dozens of trials and summarized in many reviews. Although different trials have led to somewhat different results, the picture is quite clear. Both meta-analyses and reviews of psychological treatments have come to similar conclusions about the relative effectiveness of different treatments. In general, it is agreed that relaxation and finger temperature biofeedback, either alone or in combination, are most effective. There have been fewer studies on cognitive treatments and thus the efficacy of cognitive therapy is less well-established than the other forms of psychological treatment for migraine. For example, in a recent summary of the results of randomized trials, Holroyd found that relaxation and thermal biofeedback together produced an average of $56 \%$ reduction in headache, while relaxation training or biofeedback alone produced about $35 \%$ reduction in headache. Placebo conditions produced much less effect. 
Unlike most drug treatments, the long term efficacy of psychological treatment is determined by examining patients after they have stopped formal treatment. Because of the emphasis on learning self-control or self-maintenance strategies that are to be used by the patient outside of treatment, and the use of booster sessions after intensive weekly treatment has ceased, long term changes in behaviour are encouraged. About half to two thirds of patients maintain or improve their gains 1-5 years after treatment. ${ }^{10}$

\section{UTILIZATION OF BEHAVIOURALTREATMENTS}

Although most treatment studies are done with adults, if the intervention is appropriately tailored, psychological treatments can also be effective with adolescents ${ }^{11}$ and with the elderly. ${ }^{12}$ These treatments may be particularly useful for these individuals because there is little evidence for efficacy of the newer migraine medications with children and adolescents, ${ }^{13}$ and elderly patients are more likely to have co-occurring medical problems that rule out some drug treatments. Patients who are misusing drugs or who are significantly depressed may require treatment for these problems prior to or concurrent with their treatment for migraine.

Although psychological treatments are effective, they are not widely used. Psychological services are frequently not available on health care plans. Moreover, unlike pharmaceutical treatments, there is no organized marketing arm to insure that physicians know about the treatments and use them. Although psychological treatments are expensive when delivered in their typical mode, group or therapist reduced formats have been shown to be very cost-effective. ${ }^{11}$

If psychological treatments are to be more widely used, better marketing and distribution systems will need to be developed. Innovative ideas of efficient ways for delivering services will be required.

The use of psychological treatment in combination with pharmacological interventions has not been widely studied. Mathew ${ }^{14}$ combined pharmacological and behavioural treatment (relaxation/biofeedback) in a headache clinic and found that the addition of the behavioural treatment proved only somewhat more effective than propranolol alone which, in turn, was more effective than relaxation/biofeedback training alone. A second trial $^{15}$ was conducted with patients more similar to those seen in a primary care setting, and found the combination of propranolol and behavioural treatment more effective than relaxation/ biofeedback training alone. Many of the patients who were in the combined (propranolol + behavioural) treatment were able to control their migraines on a lower dose of propranolol.

Medical treatment is always delivered in a psychosocial context. A major issue in headache treatment is compliance or adherence. Many patients do not follow the directions of their physicians. Estimates of non-compliance range from $40-60 \%{ }^{16}$ Holroyd $^{17}$ demonstrated that a brief psychological intervention, that taught appropriate use of ergotamine, improved the efficacy of the drug for the abortive treatment of migraine. A more sophisticated approach is to consider medication taking in the context of decision-making rather than compliance. Using a decision-making framework implies that patients are not just passive vessels but active participants who make decisions based on their knowledge, drug characteristics, the situation in which the headache occurs and each patient's values and priorities. We have begun a research program on how patients decide to take medication for migraine. ${ }^{18}$ It appears to be a two-stage process in which patients first decide whether or not they have a migraine. For patients without an aura, this is based mostly on pain severity and rise time of the pain. After that decision, the individual's prior experience of side effects, the person's schedule, cost of medication and effectiveness of medication are important.

\section{QUALITY OF LIFE}

The impact of migraine on individual patients is not completely captured by measurement of headache variables alone. Recently, quality of life measures have been developed for migraine and other headache. For example, Langeveld ${ }^{19}$ developed a scale for adolescents with headache. The scale measures quality of life in terms of psychological function (34 items); physical functioning (9 items); functional status (14 items); and social functioning (12 items). The scale is sensitive to headache status and sensitive to change in headache activity. The use of such psychological measurements can enhance understanding of the burden of migraine and can more precisely evaluate the effects of treatment.

Additional psychological issues that are relevant to migraine may include the transformation of frequent migraine into daily headache, and the understanding of individual differences in handicap from migraine.

\section{Conclusion}

In summary, clinical psychology can contribute to a scientific understanding of migraine in several different areas such as triggering of migraine, psychological and medical treatment of migraine, and the impact of migraine. Advances in these areas will require close collaboration between physicians and clinical psychologists.

\section{ACKNOWLEDGEMENTS}

Thanks are due to Dr. A. Purdy, A. Hennigar and J. Hatchette for assistance in developing the manuscript. Dr. McGrath is supported by an MRC Distinguished Scientist Award.

\section{REFERENCES}

1. Allen KD, Shriver MD. Role of parent-mediated pain behaviour management strategies in biofeedback treatment of childhood migraines. Behavior Therapy 1998; 29 (3):477-490

2. Gauthier J, Lacroix R, Cote A, Doyon J, Drolet M. Biofeedback control of migraine headaches: a comparison of two approaches. Biofeedback Self Regul 1985; 10(2):139-159.

3. Jacobson E. Progressive Relaxation. Chicago, University of Chicago Press, 1938.

4. Schultz JH, Luthe W. Autogenic training: a psychophysiologic approach to psychotherapy. New York: Grune, Stratton,1959.

5. Benson H. Beyond the Relaxation Response. New York: Times Books, 1984.

6. Beck AT. Depression: Causes and Treatment. Philadelphia: University of Pennsylvania Press, 1972.

7. Sullivan MJL, Bishop SR., Pivik J. The pain catastrophizing scale: development and validation. Psychol Assess 1995; 7 (4):524-532.

8. Sorbi M, Tellegen B. Stress-coping in migraine. Soc Sci Med 1988; 24:351-358.

9. Holroyd KA, Lipchik GL, Penzien DB. Psychological management of recurrent headache disorders: empirical basis for clinical practice. In: Dobson KS, Craig KD. eds. Best Practice: 
Developing and Promoting Empirically Supported Interventions. Newbury Park: Sage Publications, 1998.

10. Blanchard EB. Long term effects of behavioural treatment of chronic headache. Behavior Therapy 1987; 8:375-385.

11. McGrath PJ, Humphreys P, Keene D, Goodman JT, Lascelles MA, Cunningham SJ, Firestone P. The efficacy and efficiency of a self-administered treatment for adolescent migraine. Pain 1992; 49:321-324.

12. Kabela E, Blanchard EB, Appelbaum KA, Nicholson N. Selfregulatory treatment of headache in the elderly. Biofeedback and Self Regulation 1989; 14:219-228.

13. Hamalainen ML, Hoppu K, Santavuori PR. Sumatriptan for migraine attacks in children: a randomized, placebocontrolled trial (Do children with migraine respond differently to oral sumatriptan from adults?). Neurology 1997; 48:11001103.
14. Mathew NT. Prophylaxis of migraine and mixed headache: a randomized controlled study. Headache 1981; 21:105-109.

15. Holroyd KA, France JL, Cordingley GE, et al. Enhancing the effectiveness of relaxation-thermal biofeedback training with propranolol hydrochloride. J Consult Clin Psychol. 1995; 63: 327-330.

16. Packard RC, O'Connell P. Medication compliance among headache patients. Headache 1986; 26: 416-419.

17. Holroyd KA, Cordingley GE, Pingel JD, et al. Enhancing the effectiveness of abortive therapy: A controlled evaluation of selfmanagement training. Headache 1989; 29:148-153.

18. Purdy A, McGrath PJ, Campbell MA, Hennigar AW. Decisionmaking in patients taking sumatriptan. Headache 1997; 37(5): 327.

19. Langveld JH, Koot HM, Loonen CBAAJM, HazebroekKampschreur J, Passchier., A quality of life instrument for adolescents with chronic headache. Cephalagia 1996;16,183-196. 